INTERNATIONAL JOURNAL OF
ORGANIZATIONAL LEADERSHIP
ORGANIZATIONAL
IEADRSHIP

\title{
Exploring Chinese School Principal Experiences and Leadership Practice in Building a Professional Learning Community for Student Achievement
}

\author{
Wei Zhang ${ }^{1 *}$, Tetyana Koshmanova ${ }^{2}$ \\ ${ }^{1}$ Department of Teaching, Learning, and Educational Studies, College of Education, Western Michigan \\ University \\ ${ }^{2}$ Department of Teaching, Learning, and Educational Studies, Western Michigan University
}

\section{Keywords: \\ Principals, Elementary \\ Secondary Education, \\ Leadership Style, Academic \\ Achievement, Qualitative \\ Research}

Received

08 September 2021

Received in revised form

02 October 2021

Accepted

06 October 2021

*Correspondence:

wei.45.zhang@wmich.edu

\begin{abstract}
This basic qualitative study explores Chinese high school principals' concepts, experiences, and opinions in building a professional learning community for student achievement in China. The semi-structural interview protocol was used to collect data from Chinese principals $(\mathrm{N}=12)$ to investigate their challenges for school practical recommendations. Findings show that principals face three major challenges: (1) high exam score culture and top schools cause disengagement and lose educational core values; (2) parent high expectation causes difficulty of school growth; (3) lack of enough educational resources cause insufficient administration, teaching, and learning. In addition, findings show that principals play three major roles: (1) reconciling top-down policy intent role; (2) head role; (3) mediating role. Further, this study found that principals use three strategies to build a professional learning community: (1) communication, (2) value-based policy, and (3) engagement with a high salary and support program. Finally, this study found that school principals need to shift from the high testing score to emphasize educational core values. They also need to shift from power and authority to transformational, distributed, socialjustice, and Junzi leadership; and from student testing score sole evaluation system to integrated teaching pedagogical support system for delivering high-quality teaching. Therefore, future studies could use the exploratory sequential mixed methods research design to explore how school principals use social justice, distributed, Junzi, and transformational leadership in the K-12 school contexts in the United States and China.
\end{abstract}


Principals have a significant impact on student achievement and the overall learning environment in the schools they lead (Hallinger, 2018). They play a vital role in school reform and build a professional learning community (PLC) for student achievement (Bouchamma \& April, 2020). PLC could help schools offer whole-child development (Keung et al., 2020). PLC is also a practical approach for school principals in working with teachers for student success (Bush, 2018). Although a PLC could promote teacher learning, China has limited research (Huang et al., 2020). That is why education in China needs to be implemented.

As we know, education reform was a primarily "western" phenomenon; yet schools in the world have engaged in systematic efforts to improve the quality of the education system. Since the new set of Professional Standards for Compulsory Education School Principals from the Ministry of Education in 2013 and 2035 China new school project in 2019 (Zhu, 2019), the standards encourage principals to pay more attention to the voices of teachers in school-level decision-making as well as the interaction of power distance and coherent principal leadership (Han \& Ye, 2017). The policy states that China needs to create an educational power integrated with the school reform in the world. The school needs to develop better theories for understanding how the school responds to academic policies and practices such as leadership, curriculum, and teacher professional learning (Alduais, Deng, \& Muthanna, 2019). This phenomenon of school policy calls for school implementation. Scholars in the fields of educational sectors need to accept the challenges and opportunities of school reform to advance understanding of how cultural and institutional contexts shape the role of school principals in schooling.

Although Chinese school principals claimed that contextualizing leadership could lead to school improvement, they tend to use power in Chinese school contexts to drive improvement (Celik \& Konan, 2021). Contextually and culturally, China has been identified as a high-power top-down distance society. School principals tend to use instructional leadership and authority management (Bellibas \& Liu, 2017) for school administration. This viewing is because Chinese principals are currently asked to achieve the extraordinary and revolutionary goal of providing all children with this kind of schooling. They are being forced to continue working within factory-style models of education. Some Chinese principals are forced to place underqualified teachers to teach students, especially in rural areas, because they have difficulty recruiting qualified teachers. They often do not play an active role. For example, one-third of the teachers report that their principals only functioned as administrators; teachers rated these principals ineffective and uninvolved (Fullan, 2020).

In addition, Chinese education focuses more on mastery of knowledge, whereas American education emphasizes learning (Ravitch, 2010). China's teaching is deeply rooted in the Confucian tradition, but the ongoing socio-economic changes call for educational reform. The Confucian learning culture dominates Chinese society and the educational system (Li, 2009). Confucian culture values individuals who strive to be the perfect self, have a responsibility to the community, learn virtues, and emphasize action. The Confucian philosophy strongly influences Chinese students' minds and beliefs toward learning, such as being humble with knowledge (Yuan, 2013). Chinese education heavily relies on testing and memorization which cause many issues. For example, high school teachers complain that they sacrifice weekend hours to help students. Students are under stress, depression, and suicidal tendencies (Zhao et al., 2015). Consequently, principals emphasize standardized examination scores because they 
believe only a higher score can increase the school's social image and that higher scores are synonymous with prestigious schools and success.

Moreover, school principals lead teachers to conduct "devil training" to obtain top scores. The "devil training" means that teachers guide the students to do the mock practice testing from a morning at 8 am to an evening at $11 \mathrm{pm}$ from Monday to Friday. As a result, students gain higher scores but lose creativity and critical thinking skills (Zhao, 2014). Most school principals do not allow students to use computers or limit the time for teachers to use videos or applications for teaching. Seeking higher scores often undermines educational core values such as creativity (Noddings, 2013). These academic situations cause students to lose creativity, critical thinking, originality, and individualism (Shulman \& Sherin, 2004). For example, the Programme for International Student Assessment (PISA) in 2009 and 2012 reported that Chinese education produces the highest test scores(Tan, 2017), but it neglects the core values (Ravitch, 2020; Tan, 2013).

Although Chinese principals want to be more democratic leaders, they still use their power to improve schools. They know the purpose of education is to assist students in discovering who they are, where they are, and how they achieve their goals in life (Angelle et al., 2021). However, because they are executors of government policies, they must maintain an authoritarian style and not communicate, participate, or collaborate with colleagues at school. They vigorously emphasize honesty, courage, self-sacrifice, comradeship, loyalty, and patriotism, but these virtues are often badly misdirected (Koshmanova, 2007). It has been found that penalties, shame, and threats rarely work to improve student performance. Thus, the school leader needs to have volumes of materials that could guide in-service teachers' education.

As a result, school principals in China concentrate on preparing students for college. Due to the demand for high testing scores, they have difficulty building a PLC for teachers for student achievement. PLC in China is an early stage. Although Chinese education produces high scores on examinations, this teaching does not prepare students for their complete living, their development of a sense of collective responsibility, or how to apply knowledge for life (Ravitch, 2010). That is why Chinese education needs to emphasize the importance of deep learning and teaching for creativity, communication, character, critical thinking, and the role of principalship in leading school development in the 21st century (Fullan \& Duignan, 2012). Thus, Chinese school principals must foster a professional learning community by working with teachers, parents, and students in providing a high quality of education for students in the high-power distance school contexts.

Thus, this basic qualitative study is aimed to explore the experiences of Chinese school principals to build a learning community by using transformational leadership, value-added learning, and interactions between school stakeholders for student achievement. The study further investigates the role of school principals by analyzing the conception and interaction as being a school principal in leading school daily practice (Creswell, 2007). This study used descriptive and interpretative approaches to analyze the school principals' experiences, beliefs, opinions, and views through coding, categorizing, and synthesizing (Crotty, 1998; Saldana, 2018). Therefore, to fill in the gap in the literature, the four research questions were guided in this study: 
1) What are the challenges for school principals to lead the secondary high school improvement for student achievement in the high-power distance school contexts?

2) What are the major roles for school principals to improve the quality of teaching and learning for student achievement in the high-power distance school contexts?

3) How do the school principals understand and interpret their experiences in creating a professional learning community for student achievement in the high-power distance school contexts?

4) What are the practical recommendations for school principals to reconceptualize the school leadership framework in leading school improvement for student achievement in the high-power distance school contexts?

Since the research questions above are descriptive, we collected the primary data through one-on-one zoom interviewing with the Chinese participants. We used semi-structured and open-ended interviews to collect data to answer the research questions.

\section{Method}

\section{Overview Research Design}

The basic descriptive qualitative inquiry was employed to analyze and explore the Chinese school principals' experiences, perceptions, opinions, beliefs, and values in leading school improvement (Lincoln \& Guba, 1985). This study explores the school principals' perceptions, attitudes, and opinions in their role. Crotty (1998) confirmed that descriptive qualitative study contributes to the school implementation, appreciates their expertise, and builds their understanding.

We also employed descriptive and interpretive to naturally manage and analyze the interview data (Crotty, 1998). The interpretive approach in this qualitative research design devotes an entire study of concepts, assumptions, expectations, beliefs, and theories that support research purpose as a critical part of research design (Creswell, 2007). We also used the descriptive approaches with semi-structured protocol interviews to collect, analyze, and interpret interview data because the study explored the school principals' experiences.

Besides, we used Saldana's coding approach to merge the theme, sub-theme, and categories with selected codes to respond to the research questions. Therefore, the interpretive and descriptive analysis approaches were used to analyze the participants' experiences, beliefs, and opinions through coding, categorizing, and synthesizing the study (Adu, 2019; Saldana, 2018).

\section{Positionality and Participants}

Through data analysis, Creswell (2007) pointed out that positionality significantly impacts informants' access and understanding of experiences, beliefs, and perceptions. We have received higher education in western and eastern cultural contexts and one of us worked in China in several high schools for over twenty years, including twenty years in teaching and eight years in administrating in the educational contexts. We understand the educational reality and observe the academic environment, such as teacher pressure, student learning pressure, and insufficient educational resources in China's high-power distance learning environment. We also understand qualitative studies in various disciplines, such as data collection, analysis, research design, self-reflexivity, and trustworthiness (Saldana,2018). 
We used the semi-structured and open-ended interview protocol to collect school principals' experiences, opinions, and conception through one-on-one Zoom interviews. The interview process was to record the information through a recorder and store the data with a password in the cloud for security protection. Creswell (2007) stated that researchers developed backup copies of computer files and used high-quality tapes for audio-recording information during interviews and preserving participants' anonymity while doing interviews (Saldana, 2018).

Besides, this study randomly recruited twelve secondary high school principals $(N=12)$ in China. The study has used the participant's anonymity to understand the school principals' lived experiences in China's Confucian context (Patton, 2015). Specifically, purposive sampling and snowball sampling were recruited via an invitation letter distributed to the potential participants. The invitation letter included the contents of the purpose of the study, confidentiality, voluntary withdrawal, consent form, and researchers' information (Lincoln \& Guba, 1985). We randomly sent 35 invitation letters to the potential participants; however, we only received seven responses. Then, we used snowball data methods to recruit the other five participants based on the participant's recommendation. Therefore, twelve participants $(\mathrm{N}=12)$ who were working in the Chinese secondary school and agreed in the study within the signed consent form were employed in this study. There are six male and six female participants. Their age ranges from 28 to 70 years old. They have experience from 2 to 30 years of being school principals in China. The lower age is 28 years old, and the highest experience is 30 years working experience, respectively shown in Table 1 .

Table 1

Demographic Participants of School Principals in China

\begin{tabular}{llllll}
\hline Principal Code ID & Age & Gender & Level of Education & Years of Experience & Position \\
\hline P1 & 65 & Male & BA & 25 & Principal \\
P2 & 54 & Female & BS & 8 & Vice Principal \\
P3 & 38 & Female & MA principal & Principal \\
P4 & 70 & Male & BA & 30 & Principal \\
P5 & 66 & Male & BA & 10 & Vice Principal \\
P6 & 45 & Male & MED & 9 & Principal \\
P7 & 46 & Male & Ed.S. & 10 & Vice Principal \\
P8 & 36 & Female & MS & 7 & Principal \\
P9 & 52 & Female & BA & 20 & Principal \\
P 10 & 38 & Male & MBA & 11 & Vice Principal \\
P 11 & 28 & Female & BS & 2 & Vice Principal \\
P12 & 39 & Female & BS & 5 & C \\
\hline
\end{tabular}

\section{Data Collection Procedures}

We gathered all the signed consent forms from the participants per the ethical requirements of the human study. During the consent process, we invited the participants to join the average of 45 minutes interviews. During the interview, we recorded with digital recorders and transcribed it verbatim. We conducted a one-on-one interview through semi-structural and open-ended conversation with audio recorded from February 2020 to May 2021 through a zoom meeting (Merriam \& Tisdell, 2016).

Specifically, we used the interview questions to collect the data. We developed a standard interview protocol for Chinese school principals. Existing literature on school principals facing the challenges associated with leading school improvement and practice and the theoretical study perspectives informed the development of the interview protocols (Hallinger, 2020; Walker \& Dimmock, 2000). The questions included in the protocol sought to illuminate the 
administrator's understanding of the content area they supervised, their knowledge of the subculture within which that understanding was situated, and the principals' perceptions of the feedback they received.

In addition, the protocol for principals sought to identify what feedback administrators provided to classroom teachers. The protocol for classroom teachers asked them to describe the various ways in which administrators provided them with feedback about their instruction or to recall specific instances when an administrator offered feedback about their practice. The principal interview protocols were adjusted to reflect the principals' specific content area. The 12 interviews reached $92 \%$ saturation, and randomly selected could reach 96\% saturation in codes (Guest et al., 2006; Hennink, Kaiser, \& Marconi, 2016). Therefore, the questions are: (1) would you tell me anything about yourself and your working experiences? (2) what challenges do you meet in your professional career in school? (3) what are your leadership roles in school improvement? (4) what are the significant factors or values for school improvement? (5) how do you face your challenges in leading school development? (6) what elements do you think are important for school principals' practice? (7) what practical recommendations do you want to provide for school improvement? (8) how can you build a professional learning community? (9) is there anything that I have not asked you want to share with me?

\section{Data Analysis}

The first and second cycle coding methods were employed to analyze this study's interview transcripts, field notes, memos, reflective journals, and observation materials (Adu, 2019). The transcripts and field notes were uploaded into the computerized-aided qualitative analysis software, N-Vivo 12, to code, analyze, categorize, and synthesize the major themes and categories (Creswell, 2007). Specifically, the first coding cycle was to read transcripts to classify school principals' responses into the coding, analyzing, categorizing, and synthesizing. Specifically, we read and re-read the transcripts line by line in the first cycle to identify the categories and subcategories. The second cycle was to categorize and develop the themes through interaction and analytic memos to answer the research questions.

Then, we compared the categories that were coded. During the coding, connections were made using the iterative process that involved multiple readings in gaining a more in-depth interpretation of the meaning of the verbatim transcripts data. In the second data analysis cycle, we created themes and sub-themes through interpretative focusing coding (Adu, 2019) and an analytic memo. Memo creation identified relationships with other categories, concepts, and reflections in my coding process. The analytic memos on the way of the analysis process were used to document, reflect, and capture emergent patterns, concepts, and themes (Saldana, 2018).

Finally, the credibility of the data was verified by a member check (Denzin \& Lincoln, 1994). We also used the transcripts and fields notes to code the data with a coding process to enhance trustworthiness and credibility (Denzin \& Lincoln, 2005). In addition, we generated the reflexive memos to recognize and bias created a space where the participants told their own story in their own words, utilized multiple data sources, and solicited thick and rich descriptions. We also developed themes and created a research audit trail to ensure its quality. We also invited one of the Ph.D. candidates to ensure the data is clear enough and accurate and all materials audited (Denzin \& Lincoln, 2005). Finally, we strictly followed the qualitative research disciplines to ensure consistency and trustworthiness in this study. 


\section{Results}

The results regarding school principals' experiences and leadership practice in a secondary school in China were presented per the research questions shown in the table accordingly.

\section{1) What are the challenges for school principals to lead the secondary high school improvement for student achievement in the high-power distance school contexts?}

Aimed to answer the first research question, we emerged the three major Chinese principals' themes in leading school improvement. The themes are:

1. High exam score culture and top schools cause disengagement and lose educational core values.

2. Parent high expectation causes difficulty of sustainable school growth.

3. Lack of enough educational resource causes insufficient administration, teaching, and learning.

Therefore, we presented the themes associated with the category in Table 2. Table 2

Major Themes of Challenges for Chinese School Principals with Categories and Codes Selected with Frequency

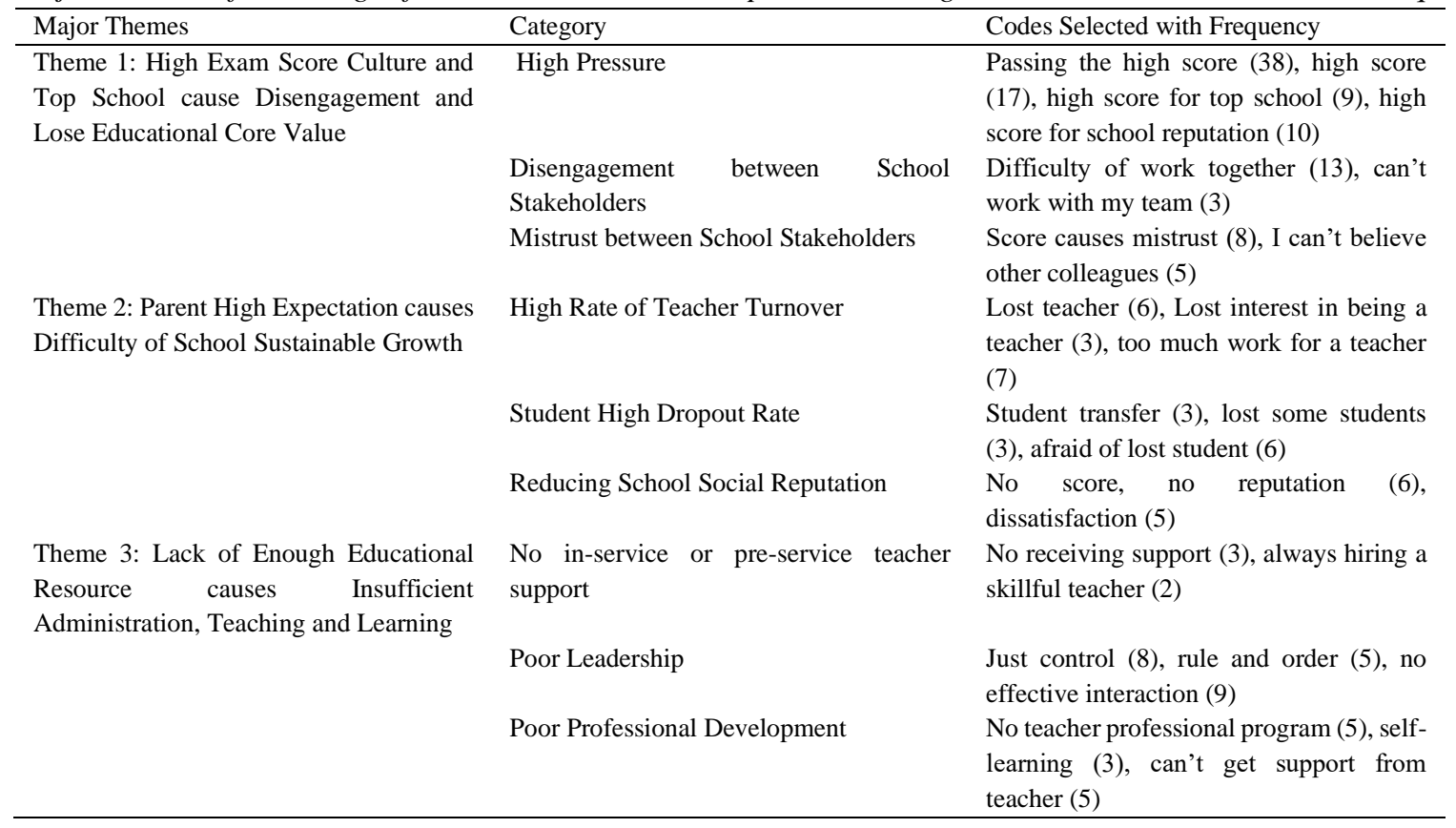

Table 2 shows that Chinese school principals face three major challenges discovered in this study. First, most participants pointed out that they meet the massive challenges is to cultivate students to pass the exam with the highest score. The highest score symbolizes a gate for students to receive a college offer from the top universities and increases its reputation. However, most increased score training causes principals and teachers to have much pressure. Therefore, we selected quotes from the participants to support the findings below.

P1 said: "only if the school students pass the exam with the highest score in the college national entrance exam, school principals could increase school reputation and also receive a welcoming configuration and support from parents and teachers."

P7 said: "I want all my students to pass the exam with the highest score, but in reality, it is not for all." 
P8 said: "I can only build trust if I can help students pass the exam."

P9 said: "...high score in an exam makes me headache... therefore, it causes mistrust among students, teachers, and parents, I think."

Those quotes that we selected above represent that Chinese school principals face the big challenge of cultivating students to pass the exam with the highest. The highest score training also causes pressure, mistrust, and disengagement among the principals, teachers, parents, and students.

Second, most participants indicated that parents' high expectations cause them to feel difficulty in leading school sustainable growth for three reasons: high rate of teacher turnover, student high dropout rate, and reducing school social reputation. To prove what we have found in this study, we directly selected quotes from the participants shown below.

P6 said: "recently, my school faced trouble because most outstanding teachers redesign their job. This viewing is because they said they are boring to help all the students pass the exam with the highest score and enter the top university. They said that they cannot help all to the top schools."

P10 said: "I think the essence of education is to train a student to become a good person, a human being, or well-being. However, I understand the real situation is that students have no highest exam score and no chance to enter prestigious schools. My school surely loses reputation and loses all things such as student dropout, parents complain."

The quotes selected from the principals indicated that Chinese school principals face the challenge of the high expectations from the parents. These expectations cause them to lose confidence, trust, support, and order in leading school improvement.

Third, most Chinese school principals realize that they lack practical educational resources. The insufficient resources cause them to have difficulty in administration, teaching, and learning evaluation. We selected the relevant quotes from the participants to support the findings below.

P2 said: "I sometimes really feel that I do not want to talk with teachers, parents, and students. I want to let them know they need to work out to reach the school goal."

P4 said: "I want to build some professional programs for my teachers. But I have no funding from the school boards."

Therefore, my findings found that Chinese school principals face the three major challenges discussed above. The challenges require them to play the different roles in the research question 2 explored.

\section{2) What are the major roles for school principals to improve the quality of teaching and learning for student achievement in the high-power distance school contexts?}

The findings revealed that principals play the three major roles, as shown in Table 3. 
Table 3

Major Themes of Roles for Chinese School Principals with Categories and Codes Selected with Frequency

\begin{tabular}{|c|c|c|}
\hline Major Themes & Category & Codes Selected with Frequency \\
\hline \multirow[t]{3}{*}{$\begin{array}{l}\text { Theme 1: Reconciling Top-Down Policy } \\
\text { Intent Role }\end{array}$} & Policy Implementation & $\begin{array}{l}\text { Implementing MOE policy (28), policy in } \\
\text { order (5), importance of educational law } \\
\text { (3) }\end{array}$ \\
\hline & $\begin{array}{l}\text { Too many out of school instructional and } \\
\text { pedagogical meeting }\end{array}$ & $\begin{array}{l}\text { Too many meetings (23), no time for } \\
\text { instruction (5), government meeting ( } 3 \text { ) }\end{array}$ \\
\hline & No flexibility & No change (5), just follow (6) \\
\hline \multirow[t]{3}{*}{ Theme 2: Head Role } & Power and Authority & $\begin{array}{l}\text { Control (10), power for order (16), be } \\
\text { followed (3), force ( } 2 \text { ) }\end{array}$ \\
\hline & Rule-based Governance & Follow rule in order $(13)$ \\
\hline & Top-down Instructional Evaluation & $\begin{array}{l}\text { Principals' decision for all things in } \\
\text { school (15), principals' observation for } \\
\text { evaluation (3), top-down hidden order (5) }\end{array}$ \\
\hline \multirow[t]{3}{*}{ Theme 3: Mediating Role } & Teacher Efficacy and Engagement & $\begin{array}{l}\text { Making teachers feel good (8), teachers in } \\
\text { order (5), teachers for work with others } \\
\text { (3) }\end{array}$ \\
\hline & Professional Learning Community & $\begin{array}{l}\text { Learning from other school members (6), } \\
\text { meetings and workshop (5) }\end{array}$ \\
\hline & Monitoring the School-level Practice & $\begin{array}{l}\text { Monitoring school daily operation (3), } \\
\text { classroom observation (5), individual } \\
\text { talks (3) }\end{array}$ \\
\hline
\end{tabular}

Table 3 shows that Chinese school principals play different roles in Chinese secondary school administration. First, Chinese school principals must play the reconciling top-down policy intent role in leading secondary school operations. According to the China Ministry of Education (2013), they have emphasized the five principles: morality first, talents cultivation orientation, development, emphasis on abilities, and life-long learning (Liu, Xu, Grant, Strong $\&$ Fang, 2017). Therefore, we selected the relevant quotes from the participants to see how Chinese school principals play the first major role below.

P3 said: "I have to guide my school in using the educational policy, curriculum, and expectation from the ministry of education."

P5 said: "I have so many meetings which are not related to my pedagogical instruction in administration, teaching, and learning. But I have to attend all the meetings."

P12 said: "I must make sure all my administration works follow the government regulation, educational policy, and all their expectation."

Those quotes selected above show that Chinese school principals need to make sure all their job performance must obey government regulation. Since China is a high-power distance and Confucian educational philosophy dominates the school setting, Chinese school principals usually play the head role in school management.

Second, Chinese school principals play the head role by using their power and authority, rule-based governance, and top-down instructional evaluation. We selected relevant quotes from participants shown below.

P1 said: "I am a head in the school. All they [teachers, students, and staff] have to follow the school rule. No excuse to me."

P9 said: "I always show my power and authority in school. I do not want to listen to different voices against the school regulation ad educational policy."

The quotes selected above show that Chinese school principals often use an authoritarian leadership style in school administration. However, the vice principals may play a different role discovered in my study. 
Third, Chinese school principals, especially vice principals, play a mediating role in school administration. To address the mediating role of the vice principals, we selected quotes from them shown below.

P2 said: "I think I surely need to enact what the principal told me and encourage teachers to perform well in their teaching. I think I am a mediator in performing my job obligation."

P11 said: "I often have a call with parents and listen to their voices. By doing so, I can request help from the principal in my school."

Therefore, this study found that school principals usually play the reconciling top-down policy intent, head, and mediating roles. These roles are related to the Chinese social-cultural and educational conditions in China. Since China is an interpersonal community, Chinese school principals need to respond to their challenges associated with the leadership role in creating a professional learning community for delivering high-quality teaching and learning. Their responses illustrated in research question 3 followed.

\section{3) How do the school principals understand and interpret their experiences in creating a professional learning community for student achievement in the high-power distance school contexts?}

To answer research question 3, the three major themes are communication, value-based policy, and engagement, which emerged and are shown in Table 4.

Table 4

Main Themes of Strategies for Chinese School Principals with Categories and Codes with Frequency

\begin{tabular}{|c|c|c|}
\hline Major Themes & Category & Codes Selected with Frequency \\
\hline \multirow[t]{3}{*}{ Theme 1: Communication } & $\begin{array}{l}\text { Equal Dialogue is an effective way of } \\
\text { dealing with conflict }\end{array}$ & $\begin{array}{l}\text { Chat (3), conversation (5), individual talk } \\
\text { (6), message (7) }\end{array}$ \\
\hline & $\begin{array}{l}\text { Building Trust is the foundation of } \\
\text { effective communication }\end{array}$ & Trust as a key (8) \\
\hline & Interaction between Stakeholders & $\begin{array}{l}\text { Interaction with teachers (8), interaction } \\
\text { with parents (19), interaction with } \\
\text { students (3) }\end{array}$ \\
\hline \multirow{4}{*}{$\begin{array}{l}\text { Theme 2: } \\
\text { Leadership }\end{array}$} & Chinese Confucian Foundation: & Confucian culture (26), Ren, Yi, Li, Zhi, \\
\hline & Benevolence, Justice, Wisdom, and Faith & Xin (6), Chinese traditional culture (3) \\
\hline & Encouragement and Companionship & $\begin{array}{l}\text { Encouragement (5), companionship (3), } \\
\text { collaboration (6) }\end{array}$ \\
\hline & Respect & Respect (15), listening to other views (8) \\
\hline \multirow[t]{3}{*}{$\begin{array}{l}\text { Theme 3: Engagement with a High Salary } \\
\text { and Support Program }\end{array}$} & $\begin{array}{l}\text { Performance Appraisal with equality and } \\
\text { respect }\end{array}$ & $\begin{array}{l}\text { No fair to my work performance (9), I } \\
\text { want to get equal treatment (5) }\end{array}$ \\
\hline & High Salary and Bonus System & $\begin{array}{l}\text { Unfair of my wage (6), low bonus in my } \\
\text { extra work ( } 8 \text { ) }\end{array}$ \\
\hline & Professional Learning Program & $\begin{array}{l}\text { No chance to receive professional } \\
\text { learning (6), hope to have chance to } \\
\text { receive further training ( } 7) \text {, I want to learn } \\
\text { something new for my teaching (6) }\end{array}$ \\
\hline
\end{tabular}

Table 4 shows that Chinese school principals use the three major themes to create a professional learning community for student achievement. First, Chinese school principals use communication tools to deal with conflict, build trust, and interact with school stakeholders, such as teachers, parents, staff, and students. Therefore, We selected the relevant quotes to support it below.

P1 said: "I think communication is an effective tool for me to deal with school issues always." 
P3 said: "I build trust-based relationships with some of the parents, teachers, and students in using the conversion tool."

P5 said: "for me, informal chat is a good way to get the information, and to work with teachers, parents, students, and staff in a way."

The quotes above show that Chinese school principals believe that communication is an effective tool for them to lead the school improvement and deal with the school challenges. This finding is compatible with the Chinese interpersonal social-cultural norms.

Second, Chinese school principals prefer to use the value-based policy and leadership in leading school improvement and building a professional learning community for student achievement. Therefore, we selected quotes to support this finding.

Pl said: "I believe the Confucian culture, such as Ren, Yi, Li, Zhi, and Xin, is important to guide the school improvement. By doing so, I think it should be welcomed by all the members in my school community."

P7 said: "I think I may less emphasize my power, but I have power in leading school. Instead, I tend to encourage my school members to reach the school goal."

P12 said: "I think always to keep respect others in my community, which is an important discipline for me."

Those participants above point out that school principals need to promote educational core values besides preparation for high exam scores. That is why principals always need to maintain a relationship with the school members for sustainable school growth.

Third, Chinese school principals need to connect with the teachers through performance appraisal with equality and respect, a high salary and bonus system, and a professional learning program. Therefore, we selected the quotes from the participants shown below.

P9 said: "I think I need to create a performance appraisal system to motivate teachers to work hard to reach the school expectation."

P11 said: "I think I need to create a professional learning program, such as in-service teacher workshop, conference, and study group coffee, and so forth."

P12 said: "I think I need to treat all teachers in the same manner, which is important for me to work with them for school performance."

Those quotes selected above show that Chinese school principals need to use different approaches to engage with teachers to deliver high-quality teaching and ensure the school is in order. Therefore, this study provides practical recommendations for Chinese school principals to improve the school in research question 4.

4) What are the practical recommendations for school principals to reconceptualize the school leadership framework in leading school improvement for student achievement in the high-power distance school contexts?

To answer research question 4 , we found three major practical recommendations to improve the schools, as shown in Table 5. 
Table 5

Major Themes of Practical Recommendations for Chinese School Principals with Categories and Codes with Frequency

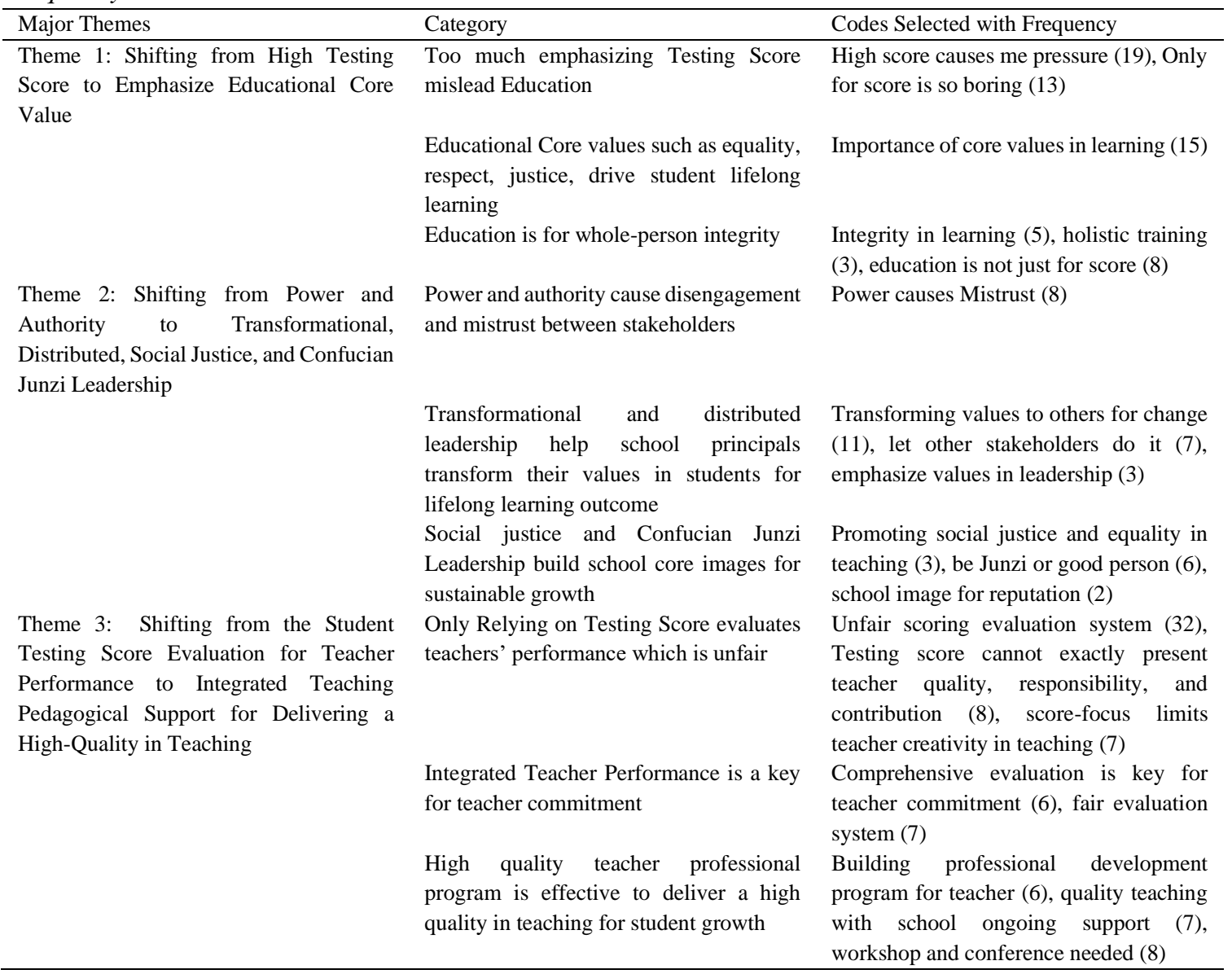

First, Chinese school principals need to promote the educational core values associated with the high exam score in Chinese schools. We selected the relevant quotes from the participants to support this recommendation.

P7 said: "I think the students need to receive the comprehensive ability in education such as analytical and critical ability, not just for the score."

P9 said: "I think the school needs to cultivate students to explore their abilities, such as communication, a sense of responsibility, efficacy, and love."

Those quotes above indicated that Chinese education needs to integrate the high exam score associated with the educational core values. With the promotion of the educational core values, school principals may need to practice the emerging leadership style.

Second, Chinese school principals need to guide the school improvement through transformational, distributed, social justice, and Junzi leadership. Therefore, we selected the quotes from the participants to support this recommendation.

P8 said:" I think I can integrate my power associated with transformational and Junzi leadership."

P12 said:" I think only if I use the transformational and distributed leadership could I create a supportive learning community." 
The quotes selected above represent that Chinese school principals need to integrate with other leadership theories and effectively lead school improvement. By doing so, Chinese school principals could drive the school for lifelong learning.

Third, Chinese school principals need to use a comprehensive pedagogical evaluation teacher support system to enhance teacher commitment for delivering high-quality teaching. Therefore, we selected the quotes from the participants to support this recommendation.

P3 said: "I think school principals need to use the comprehensive way to evaluate teacher performance. I mean, teacher performance evaluation cannot just rely on the student testing score."

P11 said:" I think if teachers receive the same treatment such as salary, bonus, and performance awarding, they indeed work for school longer commitment."

Those quotes above confirm that Chinese school principals need to use the comprehensive evaluation system for teacher performance in driving school development. Therefore, Chinese school principals are recommended to promote educational core values in teaching and learning, use transformational, distributed, social justice, and Junzi leadership, and build a comprehensive pedagogical teacher evaluation system to lead school improvement.

\section{Discussion}

The three major findings in this study were discussed. First, Chinese school principals face similar challenges of cultivating students to pass the exam with the highest testing score. The highest testing score symbolizes a great chance to study in the top university, have a better future job opportunity, and have a better journey in life. This finding is compatible with the previous studies. For example, Chinese education focuses on producing high testing scores for students (Culpepper et al., 2019). Piyaman et al. (2017) found that Chinese school principals emphasize the importance of testing score results. Their viewings are supported by Liu et al. (2019), who said that testing score results are essential for Chinese school principals to evaluate school performance, student achievement, and teacher commitment. This high testing score training is contradicted with the international scholar views such as Hallinger et al. (2014), Tyack and Cuban (1995), Darling-Hammond et al. (2020), and Koshmanova (2011). Those scholars indicated that only focusing on high testing score results could not prepare students to become wealthy. However, the findings revealed that most participants expect to integrate high testing score training and educational core values in teaching and learn for student integrity growth. This viewing is essentially new for school principals to promote lifelong learning and maintain sustainable student growth in the competitive school market in China.

Second, this study found that Chinese school principals realized that they need to build a professional learning community for school improvement, teacher commitment, and student achievement. This viewing extended and enhances the findings from Huang et al. (2020), who said that China has limited research on professional teacher learning. Therefore, this study could fill the gap on how Chinese school principals could build a professional learning community, such as using a communication channel. This finding re-emphasizes the importance of the professional learning community needed based on the previous results from Bush and $\mathrm{Ng}$ (2019), and Keung et al. (2020) in the western educational context. However, this finding suggested that Chinese school principals need to build a professional learning community to deliver high-quality teaching and learning in secondary schools in China. 
Third, this study found that Chinese school principals need to implement educational core values, authority, and emerging leadership theories as an integrated approach in leading school improvement. The emerging leadership theories include transformational, distributed, socialjustice, and Junzi leadership in the Chinese school context. This finding has proved the previous studies that school principals need to use the integrated way of leading school development. For example, Li et al. (2020), in his literature review from 2010 to 2019, showed that Chinese school leaders use transformational leadership in school change. Also, Bellibas and Gumus (2019) said that the distributed leadership could motivate teachers to commit their work and build a professional learning environment. In addition, school principals explore social justice in driving school improvement (Caliskan, 2020). Le Queux and Kuah (2020) said that school leaders in Singapore use the Junzi Leadership to serve the school stakeholders for school performance. They said Confucian Junzi (gentlemen) sought Grace and dignity by fulfilling traditional obligations: "Confucian rationalism meant rational adjustment to the world" (p.393). Therefore, they emphasize that leaders need to use the Confucian moral core, including Ren/benevolence, Yi/rightness, and Li/norms, to improve the school (Le Queux \& Kuah, 2020). Therefore, it was found that Chinese school principals emphasize the importance of the hightesting score performance and promote the educational core values for school sustainability and lifelong learning. Besides, they need to build a professional learning community associated with the western and eastern leadership theories, driving school for student achievement.

\section{Conclusion}

Three significant findings could be concluded. First, a high testing score with the desired university is the top priority for school principals in leading the school improvement in the high-power distance school contexts in China. However, this study also suggested combining the high testing score training with emphasizing educational core values in teaching and learning. Second, this study found that Chinese school principals need to build a professional learning community by integrating western and eastern school leadership theories. Chinese school principals usually use authority and power in school management. However, this study found that they prefer to combine the transformational, distributed, social-justice, and Junzi leadership in leading school improvement. Finally, school principals need to build an equal comprehensive teacher evaluation system to motivate teachers to deliver a high quality of education in teaching and learning for student achievement.

\section{Future Study Recommendation}

This study emphasizes that the Chinese school principals need to integrate high-stake testing within the educational core values in leading the school's lifelong learning. Therefore, the future research uses the descriptive qualitative study by interviewing four group participants (principal, teacher, parent, and student) to build a professional learning community for student achievement in the high-power distance in K-12 school context China. In addition, the Chinese school principals should integrate western and eastern leadership theories in school development. Therefore, we suggested that future research use the exploratory sequential mixed methods research design to explore how school principals use social justice, distributed, Junzi, and transformational leadership in the K-12 school contexts in the United States and China. 


\section{Limitations the study}

This study has two limitations. First, we could not get more participants and have a face-to-face interview due to the Pandemic. Second, we could not have the chance to ask more questions such as social justice and distributed leadership thoughts from them.

\section{References}

Adu, P. (2019). A step-by-step guide to qualitative data coding. New York, NY: Routledge.

Alduais, A., Deng, M., \& Muthanna, A. (2019, Jun). The Effect of the national plan (2010-2020) on the development of special education in China: Evidence from before-after design at a 7-year interval. Research Result. Pedagogy and Psychology of Education, 5 (3), 3-22, https://doi.org/10.18413/2313-8971-2019-5-3-0-1

Angelle, P. S., Derrington, M. L., \& Oldham, A. N. (2021, Jan). Promoting socially just schools through professional learning: lessons from four US principals in rural contexts. Professional Development in Education, 47(1), 75-88. https://doi.org/10.1080/19415257.2020.1787195

Bellibas, M. S., \& Gumus, S. (2019, Nov). A systematic review of educational leadership and management research in Turkey Content analysis of topics, conceptual models, and methods. Journal of Educational Administration, 57(6), 731-747. https://doi.org/10.1108/jea-01-2019-0004

Bellibas, M. S., \& Liu, Y. (2017). Multilevel analysis of the relationship between principals' perceived practices of instructional leadership and teachers' self-efficacy perceptions. Journal of Educational Administration, 55(1), 49-69. https://doi.org/10.1108/jea-12-2015-0116

Bouchamma, Y., \& April, D. (2020). The professional learning community to implement the results-based management approach (RBM) in Quebec. Canadian Journal of Educational Administration and Policy, 192, 77-85. <Go to ISI >://WOS:000546382300009

Bush, T. (2018). Professional learning communities and school leadership:Empowering teachers. Educational Management Administration \& Leadership, 46(5), 711-712. https://doi.org/10.1177/1741143218782316

Bush, T., \& Ng, A. Y. M. (2019). Distributed leadership and the Malaysia Education Blueprint: From prescription to partial school-based enactment in a highly centralised context. Journal of Educational Administration, 57(3), $279-295$. https://doi.org/10.1108/jea-11-2018-0206

Caliskan, O. (2020, Oct). Ecology of social justice leadership: How schools are responsive to refugee students. Multicultural Education Review, 12(4), 267-283. https://doi.org/10.1080/2005615x.2020.1842656

Celik, O. T., \& Konan, N. (2021). The relationship between school principals' empowering leadership with teachers' selfefficiancy and organizational citizenship behaivors. Egitim Ve Bilim-Education and Science, 46(206), $241-261$. https://doi.org/10.15390/eb.2020.8841

Creswell, J. W. (2007). Qualitative inquiry and research design: Choosing among five approaches. Los Angeles, CA: Sage.

Crotty, M. (1998). The foundations of social research. Los Angeles, CA: Sage.

Culpepper, S. A., Aguinis, H., Kern, J. L., \& Millsap, R. (2019, Mar). High-stakes testing case study: A latent variable approach for assessing measurement and prediction invariance. Psychometrika, 84(1), $285-309$. https://doi.org/10.1007/s11336-018-9649-2

Darling-Hammond, L., Flook, L., Cook-Harvey, C., Barron, B., \& Osher, D. (2020, Apr). Implications for educational practice of the science of learning and development. Applied Developmental Science, 24(2), 97-140. https://doi.org/10.1080/10888691.2018.1537791

Denzin, N. K., \& Lincoln, Y. S. (1994). Handbook of qualitative research. Sage Publications. http://catdir.loc.gov/catdir/enhancements/fy0658/93036736-t.html

Denzin, N. K., \& Lincoln, Y. S. (2005). The SAGE handbook of qualitative research (3rd ed.). Sage Publications. http://catdir.loc.gov/catdir/toc/ecip053/2004026085.html.

Fullan, M. (2020, Jun). The nature of leadership is changing. European Journal of Education, 55(2), 139-142. https://doi.org/10.1111/ejed.12388 
Fullan, M., \& Duignan, P. (2012). The changing and challenging context for educational leaders. Cambridge Univ Press. $<$ Go to ISI >://WOS:000306339300003

Guest, G., Bunce, A., \& Johnson, L. (2006). How many interviews are enough? An experiment with data saturation and variablity. Field Methods, 18(1), 59-82.

Hallinger, P. (2018). Bringing context out of the shadows of leadership. Educational Management Administration \& Leadership, 46(1), 5-24. https://doi.org/10.1177/1741143216670652

Hallinger, P. (2020). Science mapping the knowledge base on educational leadership and management from the emerging regions of Asia, Africa and Latin America, 1965-2018. Educational Management Administration \& Leadership, 48(2), 209-230. https://doi.org/10.1177/1741143218822772

Hallinger, P., Heck, R. H., \& Murphy, J. (2014, Feb). Teacher evaluation and school improvement: An analysis of the evidence. Educational Assessment Evaluation and Accountability, 26(1), 5-28. https://doi.org/10.1007/s11092-013-91795

Han, S. M., \& Ye, F. G. (2017, Jul). China's education policy-making: A policy network perspective. Journal of Education Policy, 32(4), 389-413. https://doi.org/10.1080/02680939.2017.1291998

Hennink, M. M., Kaiser, B. N., \& Marconi, V. C. (2016). Code saturation versus meaning saturation: how many interviews are enough? Qualitative Health Research, 27(4), 591-608.

Huang, L., Zhang, T., \& Huang, Y. T. (2020, Sep). Effects of school organizational conditions on teacher professional learning in China: The mediating role of teacher self-efficacy. Studies in Educational Evaluation, 66, 100893. https://doi.org/10.1016/j.stueduc.2020.100893

Keung, C. P. C., Yin, H., Tam, W. W. Y., Chai, C. S., \& Ng, C. K. K. (2020). Kindergarten teachers' perceptions of wholechild development: The roles of leadership practices and professional learning communities. Educational Management Administration \& Leadership, 48(5), 875-892. https://doi.org/10.1177/1741143219864941

Koshmanova, T. (2007). The Bologna process: Exploring mechanisms of European enlargement in Ukraine. In J. DeBardeleben (Ed.), The boundaries of EU enlargement. Studies in Central and Eastern Europe (pp. 165-181). London: Palgrave Macmillan. https://doi.org/10.1057/9780230591042_10

Koshmanova, T. (2011). the school of the dialogue of cultures: Legacies and prospects. Journal of Russian \& East European Psychology, 49(2), 23-28. https://doi.org/10.2753/RPO1061-0405490203

Le Queux, S., \& Kuah, A. T. H. (2020). (sic) Junzi leadership in Singapore: Governance and human capital development. Journal of Management Development, 40(5), 389-403. https://doi.org/10.1108/jmd-05-2019-0194

Li, C. Y. (2009, Oct). Where does confucian virtuous leadership stand? Philosophy East \& West, 59(4), 531-536. <Go to ISI>://WOS:000271449200008

Li, J., Shi, Z. L., \& Xue, E. Y. (2020). The problems, needs and strategies of rural teacher development at deep poverty areas in China: Rural schooling stakeholder perspectives. International Journal of Educational Research, 99, 101496. https://doi.org/10.1016/j.ijer.2019.101496

Lincoln, Y., \& Guba, E. (1985). Naturalistic inquiry. New York: Sage.

Liu, Y. B., Yuan, P., Lu, H. X., \& Ju, F. H. (2019, Oct). The effect of power on donation intention: A moderated mediation model. Social Behavior and Personality, 47(10), 1-12. https://doi.org/10.2224/sbp.8293

Liu, S., Xu, X., Grant, L., Strong, J., \& Fang, Z. (2017). Professional standards and performance evaluation for principals in China: A policy analysis of the development of principal standards. Educational Management Administration \& Leadership, 45(2), 238-259. https://doi.org/10.1177/1741143215587304

Merriam, S. B., \& Tisdell, E. J. . (2016). Qualitative research: A guide to design and implementation (4th ed). USA: JosseyBass.

Ministry of Education (MOE, 2013). Professional standards for K-9 principles. Beijing: MOE.

Noddings, N. (2013). Standardized curriculum and loss of creativity. Theory into Practice, 52(3), $210-215$. https://doi.org/10.1080/00405841.2013.804315

Patton, M. Q. (2015, Dec). Evaluation in the field: The need for site visit standards. American Journal of Evaluation, 36(4), 444-460. https://doi.org/10.1177/1098214015600785

Piyaman, P., Hallinger, P., \& Viseshsiri, P. (2017). Addressing the achievement gap Exploring principal leadership and teacher professional learning in urban and rural primary schools in Thailand. Journal of Educational Administration, 55(6), 717-734. https://doi.org/10.1108/jea-12-2016-0142 
Ravitch, D. (2010). The death and life of the great American school system: How testing and choice are undermining education. New York, NY: Basic Books.

Ravitch, D. (2010, Mar). Why public schools need democratic governance. Phi Delta Kappan, 91(6), 24-27. https://doi.org/10.1177/003172171009100607

Ravitch, D. (2020). Slaying goliath: The passionate resistance to privatization and the fight to save American's public schools. New York, NY: Alfred A. Knope.

Saldana, J. O., M. . (2018). Qualitative research: Analyzing life. Los Angeles, CA: Sage.

Shulman, L. S., \& Sherin, M. G. (2004). Fostering communities of teachers as learners: disciplinary perspectives. Journal of Curriculum Studies, 36(2), 135-140. https://doi.org/10.1080/0022027032000135049

Tan, C. (2017). Chinese responses to Shanghai's performance in PISA. Comparative Education, 53(2), 209-223. https://doi.org/10.1080/03050068.2017.1299845

Tan, C. (2013). Learning from Shanghai: Lessons on achieving educational success. Singapore: Springer

Tyack, D. \& Cuban, L. (1995). Tinkering toward Utopia: A century of public school reform. Cambridge, Massachusetts: Harvard University Press.

Walker, A., \& Dimmock, C. (2000). Leadership dilemmas of Hong Kong principals: Sources, perceptions and outcomes. Australian Journal of Education, 44(1), 5-25. https://doi.org/10.1177/000494410004400103

Yuan, L. (2013) Wise and virtuous leadership: The contribution of confucian values to business leadership. In M. J., Thompson \& D. Bevan (Eds.), Wise management in organisational complexity (pp. 106-121). Palgrave Macmillan, London. https://doi.org/10.1057/9781137002655_7

Zhao, X., Selman, R. L., \& Haste, H. (2015). Academic stress in Chinese schools and a proposed preventive intervention program. Cogent Education, 2(1), 1000477. https://doi.org/10.1080/2331186x.2014.1000477

Zhao, Y. (2014). Who's afraid of the big dragon? Why China has the best (and worst) education system in the world. JosseyBass.

Zhu, Y. (2019). New national initiatives of modermizing education in China. ECNU Review of Education, 2(3), 353-362. https://doi.org/10.1177/2096531119868069

\section{Acknowledgements}

Not applicable.

\section{Disclosure Statement}

No potential conflict of interest was reported by the authors.

\section{Funding Acknowledgements}

Not applicable.

\section{Open Access}

The International Journal of Organizational Leadership publishes open access articles under the terms of the Creative Commons Attribution (CC BY) License, which permits use, distribution, and reproduction in any medium, provided the original work is properly cited. 